\title{
DA (IN)JUSTICIABILIDADE DOS DIREITOS FUNDAMENTAIS SOCIAIS: 0 DIREITO À SAÚDE E O ACESSO GRATUITO
}

\author{
The justiciability or not justiciability of fundamental social rights: the right to health \\ and access free
}

Yuri Schneider

Camila Dalberto

Universidade do Oeste de Santa Catarina -UNOESC - Chapecó - Santa Catarina - Brasil

\begin{abstract}
Resumo: A presente pesquisa aborda a judiciabilidade dos direitos fundamentais sociais, analisando o papel do Estado na efetivação e disponibilização dos direitos fundamentais previstos na Constituição da República Federativa do Brasil de 1988. Nesse respeito, visa analisar o direito ao acesso à saúde, levando em conta os pressupostos fundamentais da dignidade da pessoa humana e do direito à vida. É sabido que compete ao Estado o dever de fornecer o acesso gratuito à saúde para toda população, respeitando seu limite orçamental denominado reserva do possível. Para tanto, será feita uma análise jurisprudencial sobre a efetividade e a concessão do acesso gratuito á determinados serviços que não são prestados na forma gratuita pelo governo, sob a ótica do posicionamento e intervenção dos tribunais de justiça na prestação à saúde, como forma de efetivação da garantia constitucional. Assim, o embasamento teórico da pesquisa se fundamenta nos princípios constitucionais, principalmente com relação à dignidade da pessoa humana e da saúde como elemento essencial para a manutenção e pleno exercício da vida. Também será abordada a dificuldade de subjetivação dos direitos fundamentais sociais, bem como sua normatização. A pesquisa foi realizada pelo método bibliográfico.
\end{abstract}

Palavras chaves: Direito a saúde e dever do Estado. Direito Fundamental. Dignidade Humana e direito à vida. Justiciabilidade. Reserva do possível.

\begin{abstract}
This research adresses the justiciability of fundamental social rights, analyzing the state's role in the effectiveness and availability of fundamental rights under the Constitution of the Federative Republic of Brazil in 1988. In this respect, aims at analyzing the right to access to health, taking into account the fundamental assumptions of human dignity and the right to life. It is known that the State has a duty to provide free health care for all people, respecting their budget are limit called the possible reserves. For both, a jurisprudential analysis of the effectiveness and the granting of free access wil be made certain services that are not provided free by the government, from the perspective of positioning and intervention of the courts of justice in the provision of health, as a means of effecting the constitutional guarantee. Thus, the theoretical foundation of the research is based on the constitutional principles, especially with respect to human dignity and health as essential to the maintenance of life and full enjoyment element. Also addressed will be the difficulty of subjectivity of fundamental social rights, as well as its regulation. The survey was conducted by the literature method.
\end{abstract}

Keymords: Right to health and duty of the State.Fundamental Right. Human dignity and right to life. Justiciability. Reservati on possible.

Revista do Direito da UNISC, Santa Cruz do Sul, v.1, n. 45, p. 02-30, jan. - abri. 2015. 


\section{INTRODUÇÃO}

O direito a saúde teve grandes avanços na sociedade brasileira após a constituição de 1988, que salienta a sua importância no exercício da vida digna. Novas descobertas tem possibilitado cada vez mais a melhoria da qualidade de vida de pacientes com graves doenças, mas, a oferta de tratamentos aos pacientes sem possibilidade de obtê-los por conta própria acaba causando um grande aumento nos custos de saúde da população, tal problemática vem criando uma discussão sobre a responsabilidade e a limitação dos direitos fundamentais referentes à vida e a saúde por parte do Estado, tendo em vista a verba orçamentária destinada à saúde e as intervenções do poder judiciário.

O Direito a saúde foi reconhecido pela Constituição Federal de 1988, como um direito fundamental de caráter social, que exige do Estado prestações para sua efetividade. Ademais, quando aliado ao caráter fundamental social emana diversas consequências em relação às políticas públicas, separação de poderes e o caráter subjetivo das prestações. Assim, a presente pesquisa busca discutir acerca da gratuidade do acesso à saúde, em contraponto com a intervenção judiciária e seus pressupostos.

Para este fim, estudar-se-á em um primeiro momento, buscamos a abordagem histórica do direito a saúde, tratando da expansão da proteção dos direitos fundamentais sociais e do avanço na proteção do direito a saúde ampliado pela Constituição cidadã através do Sistema Único de Saúde. Ainda, sendo o direito à vida obrigação negativa e também positiva do Estado, este deve adotar medidas positivas que assegurem a aplicabilidade desse direito inerente ao ser humano, que não pode ser alvo de privações. E, ainda, a importância das políticas

públicas para concretizar tais direitos e para delimitar a subjetivação do direito a saúde.

Em seguida, analisar-se-á a judicialização e seus elementos, como a reserva do possível, a realocação de recursos, o mínimo existencial, a separação de poderes e o ativismo judicial, enquanto mecanismo de efetivação do direito à saúde. Por fim, dada a exposição conceitual, a mesma será relacionada a um 
caso concreto, isto é, far-se-á análise jurisprudencial referente as demandas de saúde, identificando os motivos e os procedimentos adotados para a resolução do conflito.

\section{A SAÚdE E OS DIREITOS FUNDAMENTAIS SOCIAIS NA CONSTITUIÇÃO FEDERAL DE 1988}

Inicialmente devemos considerar que todo ser humano nasce com direitos e garantias, não devendo estes ser considerados como concessão do Estado, tendo em vista que, "alguns estes direitos são criados pelos ordenamentos jurídicos, outros são criados através de certa manifestação de vontade, e outros apenas são reconhecidos nas cartas legislativas" (SILVA, 2006). Ainda, é válido ressaltar que as pessoas como um todo devem exigir que a sociedade respeite e garanta sua dignidade e necessidades básicas fundamentais.

Nesse sentido, de acordo com Flávia Martins André da Silva (2006) os direitos fundamentais compreendem um conjunto de direitos e garantias do ser humano, que tem por finalidade tutelar a dignidade, o respeito à vida, à liberdade $e$ à igualdade para o pleno desenvolvimento de sua personalidade. Partindo dessa prerrogativa, é importante, considerar que os direitos fundamentais, e, principalmente os direitos fundamentais sociais, tem ocupado posição de destaque no contexto constitucional brasileiro.

Para Dallari (2003), a sociedade deve estar organizada de modo que busque condições que permitam a cada homem e grupo social ter o que precisa para seus fins particulares. A organização da sociedade deve ter uma finalidade, que é visar o bem de todos, bem comum sendo este um conjunto de condições da vida social que melhorem o desenvolvimento da personalidade humana, obtido de forma harmônica e garantindo a liberdade de todos.

Os direitos sociais surgiram na crise do Estado liberal, na busca por uma maior igualdade social, dando aos indivíduos prestações sociais necessárias para viver com dignidade. Distingue-se o direito social do direito de defesa, ao ponto que estes representam uma omissão do Estado, uma prestação negativa, 
enquanto aqueles exigem uma prestação positiva por parte do Estado, assegurando aos indivíduos um mínimo existencial, e pressupõem uma realização de igualdade. (ASSIS, 2012)

Os direitos sociais passaram a se desenvolver a partir do século $X X$, quando se percebeu que os direitos individuais não eram suficientes, pois sem as condições mínimas como educação, alimentação e saúde, os direitos individuais não podiam ser exercidos. Assim, observa-se que as dimensões de direitos completam-se, contribuindo todos para a realização da dignidade humana. (BARCELLOS, 2011)

Após a segunda guerra mundial, cresce a discussão a cerca dos direitos humanos, criando declarações pactos e organizações para protegê-los. O Estado passa a intervir ativamente tentando diminuir as desigualdades econômicas, assumindo a prestação de serviços fundamentais para todos, surge a necessidade de controlar os recursos disponíveis para se obter um maior proveito, levando a ação do Estado a todos os campos sociais, com o fim da guerra, o Estado precisa intervir mais ainda para restaurar as cidades e readaptar as pessoas. (DALLARI 2003)

Parece aceita a ideia de que para ser denominado direito humano, este precisa preencher algumas condições como a universalidade, a justicidade e exigibilidade, ou seja, ser garantido a todos os grupos, ter pleno acesso a justiça, e clareza de quem tem a obrigação de realizá-lo. Existe dificuldade no entendimento de que os direitos sociais, econômicos e culturais estejam qualificados nessa categoria. Há quem pense que seria possível exigir do Estado apenas que não maltratem ou dizimar os cidadãos, mas não seria apropriado requerer garantia de um padrão de vida para todos, sendo que tais direitos requereriam um aumento conseqüente nos impostos, sendo um atrevimento requerer a satisfação dos direitos humanos quando não há possibilidades de realizá-los e concretizá-los. (BONVENUTO 2010)

Os direitos sociais são previstos na Constituição Brasileira de uma forma ampla e abstrata, sendo necessária a atuação do poder público para estabelecer meios adequados de implementação. Observado isso, não há como negar o 
vinculo entre a efetivação dos direitos e os recursos públicos para o financiamento das prestações, necessitando de regulamentação através das políticas públicas como caracteriza a constituição, elaboradas pelo poder legislativo e poder executivo, por meio das quais são estabelecidos objetivos a serem alcançados para a melhoria econômica social e política, garantindo o acesso as camadas menos favorecidas, definem assim metas e meios pelos quais serão aplicados. (ASSIS, 2012) Através delas, o governo faz o planejamento da forma mais adequada, para que as áreas sociais que mais precisam sejam atendidas, e assim sejam alcançados os objetivos desejados.

Devemos incorporar a agenda social de direitos sociais nas organizações e instituições econômicas regionais e globais, pois somente assim, trazendo a baila a questão dos direitos humanos, para o cenário econômico globalizante, estaremos afastando a ideia neoliberal de colocar esses ditos direitos em segundo plano.

No contexto marcado pela globalização econômica e pela integração regional, há a urgência de incorporar a agenda social na pauta da integração regional de blocos econômicos, bem como na nova arquitetura financeira internacional.

O ordenamento jurídico brasileiro conferiu, após a segunda guerra mundial, a dignidade humana o caráter de princípio fundamental e de norma embasadora do sistema constitucional, tendo assim valor máximo, sendo a dignidade humana dotada de eficácia plena em todas as relações. (BERNARDI, 2007)

Alexandre de Morais(2003), "A dignidade é um valor espiritual e moral inerente à pessoa, que se manifesta singularmente na autodeterminação consciente e responsável da própria vida e que traz consigo a pretensão ao respeito por parte das demais pessoas, constituindo-se um mínimo invulnerável que todo estatuto jurídico deve assegurar, de modo que, somente excepcionalmente, possam ser feitas limitações ao exercício dos direitos fundamentais, mas sempre sem menosprezar a necessária estima que merecem todas as pessoas enquanto seres humanos;"

Revista do Direito da UNISC, Santa Cruz do Sul, v.1, n. 45, p. 02-30, jan. - abri. 2015. 
Sobre o mínimo existencial refere-se Barcellos (2011) dizendo que, "o chamado mínimo existencial, formado pelas condições materiais básicas para a existência, corresponde a uma fração nuclear da dignidade da pessoa humana." Sendo que dignidade humana é valor fundamental, que com a constituição de 1988 tornou-se princípio fundante e finalidade principal do Estado, este princípio associado a outros, tem por objetivo na constituição vigente, assegurar um consenso mínimo de direitos aos indivíduos e o pluralismo jurídico para as decisões, devendo necessariamente ser respeitado o consenso mínimo assegurado pela constituição, realizando da forma mais ampla a dignidade. Não respeitar o mínimo necessário constitui violação desse princípio constitucional, e no caso do não cumprimento deste, poder-se-á impor coativamente sua realização através do judiciário, para que assim seja possível garantir uma vida digna.

Caracteriza-se assim o mínimo existencial como 0 conjunto de necessidades básicas para uma vida com dignidade. A doutrina e a jurisprudência definiram os conteúdos desse mínimo de existência digna, não podendo este ser diminuído ao máximo, como garantia mínima, não está sujeito a uma reserva do possível, pois de qualquer modo, deve-se haver um mínimo de proteção para os direitos sociais que garanta a sobrevivência da pessoa dignamente. (ASSIS, 2012) Estando a dignidade respeitada terá os direitos fundamentais realizados.

Quando se fala em direito a saúde, a controvérsia a cerca do mínimo existencial torna-se muito mais complexa, pois alem de um mínimo para se viver, precisa-se do máximo para que se viva com dignidade, garantindo ao paciente o mínimo de sofrimento possível, através dos medicamentos e tratamentos médicos.( BERNARDI, 2007)

Após essa breve análise, faz-se necessário analisar a evolução, titularidade, eficácia e efetivação dos direitos fundamentais sociais, especialmente, no que tange o direito fundamental à saúde, que fundamenta o enfoque da pesquisa. A saúde não é um conteúdo inovador no ordenamento constitucional brasileiro, uma vez que, antes mesmo de ser introduzida no ordenamento jurídico a carta constitucional de 1988, já era incumbência da União legislar em defesa da saúde.

Revista do Direito da UNISC, Santa Cruz do Sul, v.1, n. 45, p. 02-30, jan. - abri. 2015. 
Considerando o patamar histórico, do direito fundamental a saúde, José Afonso da Silva (2008) relata que a primeira constituição a reconhecer o direito a saúde como fundamental ao individuo, foi a Constituição Italiana de 1948. Todavia, no Brasil, o direito a saúde se restringia as organizações administrativas de combate a endemias e epidemias, tão somente, ao se tornar objeto de um pacto, a Organização Mundial da Saúde (OMS) de 1946, concretizou o conceito de saúde como direito humano e universal, o que serviu de estimulo para o reconhecimento das constituições de outros países.

O pacto internacional dos direitos econômicos, sociais e cultuais expandiu o rol de direitos determinados pela Declaração Universal de 1948, criando obrigações aos Estados. Os direitos econômicos, sociais e culturais dependem de regulamentação pelos Estados, devendo estes tomar medidas até o máximo de recursos disponíveis para a viabilização do pleno exercício dos direitos reconhecidos, alem de adotar medidas legislativas. (OLIVEIRA 2011)

Até ser reconhecido como direito fundamental social, direito de todos e dever do Estado, um longo caminho foi trilhado. Concebidos como direitos humanos, tem carater subjetivo prima face, assim denomina Cavalheiro (2013), não sendo possível pois resolve-lo totalmente. A concepção de direito subjetivo público deve ser compreendido em duas formas essenciais, a constitucionalização desses direitos e a sua fundamentalização.

A Organização Mundial de Saúde (OMS) faz a conceituação de que"A saúde é um estado de completo bem-estar físico, mental e social, e não consiste apenas na ausência de doença ou de enfermidade." Ressaltando ainda o direito fundamental de todo ser humano de atingir o melhor estado de saúde possível, sem qualquer distinção, dependendo está da cooperação entre indivíduos e Estado, devendo o acesso ser igualitário a todos.

O direito a saúde no Brasil teve maior destaque e reconhecimento como direito de todos e dever do Estado com a promulgação da Constituição Federal de 1988, até então, os serviços de saúde eram disponíveis apenas a aqueles que contribuíssem com o sistema ou tivessem como financiar seus custos. Essa história começou a mudar a partir dos anos setenta quando, motivados pelo 
processo de redemocratização, ganharam forças os movimentos de Reforma Sanitária, da qual resultou em grande influencia na criação do SUS (Sistema Único de Saúde), o qual tem por escopo garantir acesso universal e igualitário as ações de serviços necessários a promoção, proteção e recuperação da saúde. (CAVALHEIRO, 2013)

Sendo assim consagrado como direito fundamental, e indissociável ao direito à vida, negar o acesso a saúde é descuidar a dignidade humana. A proteção do direito a saúde vincula-se aos direitos sociais estabelecidos no rol de direitos fundamentais, necessitando de prestações positivas por parte do Estado que possibilitem melhor condição de vida, para isso é preciso que o estado realize no mundo fático o que é descrito nas normas. Assim a efetividade das normas esta relacionada ao estabelecido pelas políticas públicas, sendo por meio delas 0 cumprimento das prestaçõs. (BERNARDI, 2007)

Financiado pelos tributos pagos pela sociedade, o SUS é mantido pelos recursos destinados a segurança social. Que será financiado, segundo artigo 195 da Constituição Federal, por toda a sociedade de forma indireta ou direta na forma da lei. O conjunto de normas referentes a saúde pública estipula ações do poder público para garantir o direito a todos e impor a obrigação ao Estado.

Bem como disposto na Constituição da República Federativa do Brasil em seu artigo 196 no qual dispõe, "a saúde é direito de todos e dever do Estado garantido mediante políticas sociais e econômicas que visem à redução do risco de doenças e de outros agravos e ao acesso universal igualitário às ações e serviços para sua promoção, proteção e recuperação." Cabendo sua regulamentação e fiscalização ao poder público através de terceiros, pessoas físicas e jurídicas. Garantindo o acesso igualitário mediante políticas públicas, por meio de medidas que reduzam o risco de doenças.

O Direito a Saúde atrela-se ao Direito maior defendido pela Constituição Federal Brasileira, desenhado no caput do artigo 5ํㅜ, direito inviolável à vida. E colocado no Rol de direitos Fundamentais Sociais constantes no capitulo II da Constituição em seu artigo $6^{\circ}$ da seguinte forma: "Art. $6^{\circ}$ São direitos sociais a educação, a saúde, a alimentação, o trabalho, a moradia, o lazer, a segurança, a 
previdência social, a proteção à maternidade e à infância, a assistência aos desamparados, na forma desta Constituição". E no título VIII, tratando da segurança social e das normas de saúde.

O artigo 194 refere-se a saúde quando este é abrangido pela seguridade social e assegurado no seu parágrafo único pela universalidade, uniformidade, irredutibilidade, equidade e financiamento. O artigo 197 dispõe ainda sobre a forma de execução, regulamentação e fiscalização dessas políticas garantidoras de direitos, podendo ser ela feita pelo poder público (forma direta) ou por iniciativas privadas (através de terceiros). Surge ai o SUS - Sistema Único de Saúde, previsto constitucionalmente no artigo 198, estipulando a descentralização com direção a cada esfera do governo, o atendimento integral, priorizando ações preventivas, e outras atribuições regulamentadas na lei 8.080/90. A Constituição Federal de 1988 estabelece ainda (artigos 23-30), que cabe a união, Estados, municípios e Distrito Federal a assistência pública e especialmente ao município o de legislar, sobre a defesa da saúde, cabendo ao município ainda aplicar a prestação de serviços com a cooperação técnica e financeira dos demais. (SCAFF, 2011)

A Lei 8.080/90, a qual cuida da regulamentação do Sistema Único de Saúde estabelece em seu artigo $2^{\circ}$ que "A saúde é um direito fundamental do ser humano, devendo o Estado prover as condições indispensáveis ao seu pleno exercício." A citada lei observa ainad que os níveis de saúde expressam a organização social e econômica do país, devendo garantir as pessoas e a coletivivdade o bem estar físico, mental e social.

A lei de regulamentação do SUS ressalta no artigo $6^{\circ}$ que estão incluídas na atuação do SUS, a assistência integral inclusive a farmacêutica. E dispõe que será garantida a integridade de assistência com o conjunto de serviços preventivos e curativos, individuais ou coletivos em cada caso com seu nível de complexibilidade. 


\section{A EFETIVAÇÃO DA SAÚDE: AS POLÍTICAS E A JUSTICIABILIDADE}

Os direitos sociais inscritos na constituição geraram a ânsia da sociedade pelo reconhecimento de seus direitos, mesmo antes do estabelecimento das normas infralegais estabelecerem melhor sua aplicação, na tentativa de ampliar o alcance desses direitos, através do legislativo ou do Executivo, além do controle jurisdicional, não apenas por decisões do STF, mas por qualquer outro poder judiciário na tentativa de concretizar tais direitos à sociedade. (SCAFF, 2011)

As políticas públicas são processos pelos quais a sociedade pode organizar-se, por meio de processos envolvendo decisões políticas que visam enfrentar os problemas da comunidade e da sua segurança. Procopiuck (2013, p. 139-140), expressa sua visão sobre ações públicas dizendo ainda, "A função específica de uma política pública prover orientações normativas guiadas por valores e por finalidades, para a elaboração de estratégias, programas e planos que procuram adequar meios para atingir determinados fins".

As políticas públicas, necessárias para a regulamentação dos direitos sociais, dependem das possibilidades financeiras dos Entes Federados para sua implementação. O planejamento financeiro feito através do orçamento é um instrumento pelo qual o Estado fixa os objetivos que devem ser atingidos com tais recursos. Tornando-se os custos de realização um limite para a concretização, uma restrição ao direito social. (ASSIS, 2012.)

Realizados os direitos sociais de forma gradual, e dependendo estes de possibilidades orçamentarias do Estado, quando comprovada a incapacidade do Estado em amparar financeiramente a efetivação desses direitos não se pode exigir uma efetivação imediata, porem, é ilícito manipular as atividades financeiras de forma que crie obstáculos à realização e preservação dos direitos em defesa do cidadão em condições mínimas de existência. Assim sendo, não pode a reserva do possível ser invocada pelo estado para exonerar-se do cumprimento de suas obrigações, com o risco de causar a extinção do sentido essencial do direito. (VOLPE, 2012) assim os gastos devem ser destinados preferencialmente ao mínimo essencial em primeiro plano.

Revista do Direito da UNISC, Santa Cruz do Sul, v.1, n. 45, p. 02-30, jan. - abri. 2015. 
Os direitos sociais estão previstos como direitos Fundamentais, portanto, possuem eficácia e sua efetivação deve ser buscada de forma séria, sem a invocação de argumentos ou desculpas injustificáveis. O papel dos legisladores ordinários na escolha e concretização das politicas públicas são de fundamental importância merecendo estas decisões especial cuidado sendo elas meio para a busca da efetivação do direito social, definindo metas e meios pelos quais serão aplicados, criadas pelo governo, elas buscam definir as áreas sociais com maior prioridade de atuação, traçando objetivos a serem alcançados através dos meios disponíveis no momento.(ASSIS, 2012)

Observa-se, portanto, que não pode o estado alegar a qualquer momento a reserva do possível, pois deve ser respeitado ao menos um mínimo para o exercício de uma vida digna. Podendo ser alegado apenas se demonstrar que tal decisão causará mais danos do que benefícios para a concretização dos direitos fundamentais. (ASSIS, 2012)

Ao tratar de competências, faz-se necessário observar a incumbência do legislativo e do executivo de estabelecer as políticas públicas por meio das quais será assegurado o direito à saúde, cabendo ao judiciário o controle de judicialidade e do cumprimento das políticas, além de suprir a inexistência ou insuficiência garantindo o mínimo de prestação, que garanta a existência do indivíduo, distribuída universalmente e igualmente. Para o STJ, o fornecimento deve ser feito a todos, ou ao grupo que dele necessitar. (SCAFF, 2011)

Assim, caberá ao poder legislativo a votação e aprovação das leis, bem como o modo como as verbas serão gastas. E ao Poder Executivo caberá o investimento das verbas públicas na execução dos orçamentos e dos planos do governo decidindo sobre a aplicação dos recursos. Entretanto, a norma não consegue prever todas as possibilidades do cotidiano gerando assim alguns conflitos quanto à aplicação. Nesse contexto, entra o judiciário em uma busca por solucionar o litígio, o que acontece com muita frequência nas políticas públicas de saúde. (PETERSEN,2011)

A judicialização significa o debate e a decisão de questões de grande relevância social, política e moral pelo poder judiciário, e não como o tradicional, 
pelo Executivo e Legislativo. Esta discussão constitui uma mudança na forma de pensar, é um fenômeno mundial fruto de circunstancias diversas, entre elas a importância do reconhecimento de um poder judiciário com independência sendo este essencial para a democracia. A judicialização decorre do desenho institucional do país, não é opção do judiciário, mas obrigação de pronunciar-se quando provocado sobre tais questões. Entretanto, é importante observar se incorre em ativismo judicial, o qual é associado a ideia de participação judicial ampla que acaba por causar interferência no espaço dos demais poderes.( BARROSO, 2012)

A justiciabilidade, para Juliana Soares (2014), é a possibilidade de buscar junto ao poder judiciário os direitos, sendo assim, a justiciabilidade busca a efetivação dos direitos por meio de mecanismos jurídicos. A eficácia jurídica, como poder de exigir judicialmente direitos fundamentais sociais encontra problemas no judiciário e em toda a sociedade em relação a disponibilidade de recursos financeiros por parte do Estado.

As atividades são programadas para acontecer com determinado recurso objetivado nas leis orçamentárias, e ai entramos em debate, até que ponto o Estado tem o dever de fornecer medicamentos caros, muitas vezes concedidos aos indivíduos através de ações individuais, sob risco de vida e de afetar a dignidade humana preceito fundamental na constituição brasileira.

Há diversos conflitos sobre a escassez de recursos, vez que uma realização plena e incondicionada dos direitos sociais são apenas uma utopia, sendo os custos um limite para sua concretização, a restrição do reconhecimento do direito social causada pela falta de recursos nomeada reserva do possível, sendo ela a proporcionalidade de recursos financeiros disponíveis, é o que o individuo pode exigir, limitando a realização plena do direito. (ASSIS, 2012)Sabese que este não pode ser saciado de todo, tendo em vista as infinitas necessidades da população, e o escasso recurso estatal. Nenhum Estado conseguiria prover a todos tudo o que necessitam. Mas o mínimo essencial para uma vida digna deve ser respeitado.

Revista do Direito da UNISC, Santa Cruz do Sul, v.1, n. 45, p. 02-30, jan. - abri. 2015. 
Inúmeras são as criticas quanto a atuação do judiciário, sob o argumento de que os juízes não eleitos, e portanto não representariam a vontade do povo. Cabe a cada poder interpretar segundo a constituição sua atuação, cabendo em caso de divergência a palavra final ao judiciário, porem, nem em todas as matérias, pois deve-se observar quem está mais habilitado para a tomada decisões na matéria em debate, também há a questão de que o juiz prepara-se para a análise em casos concretos, fazendo uma microjustiça, não avaliando o impacto de suas decisões na esfera econômica de prestações de serviços públicos. Além disso trás uma doze excessiva de politização ao judiciário.(BARROSO, 2012)

Ana Paula de Barcellos (2011), entende que o judiciário pode determinar com fundamento na constituição e independente de ação da administração ou do legislativo o fornecimento de prestações de saúde, ao menos no que se refere ao mínimo existencial.

Instrumento de reparações de atos e omissões dos demais poderes, o poder judiciário estaria dentro de suas atribuições, não atingindo a separação de poderes, não devendo está teoria servir como empecilho na realização dos direitos, sendo que a separação de poderes busca a limitação do poder do estatal, permitindo o acesso aos indivíduos e grupos sociais. Não sendo adequado intervir no acesso dos indivíduos e grupos sociais por meio do reclame ao judiciário no momento em que os cidadãos estão exercendo sua maior intervenção na defesa de direitos. (BONVENUTO, 2010)

Para ASSIS(2012), não há o que se falar em violação do princípio de separação dos poderes, vez que, a constituição legitima o poder judiciário ao controle dos demais poderes caso estes omitam-se ou violem direitos fundamentais. Para o autor, o direito a saúde deve ser aplicado imediatamente e exigível por todo cidadão independente de regulamentação, considerando a participação do judiciário de grande importância para a transformação social.

Entretanto, expõe ASSIS (2012) que os direitos fundamentais assumem distintas formas de eficácia pelas diferentes funções que exercem e das técnicas usadas para sua positivação. Assim, a competência para aplicá-las no caso de 
descumprimento caberia ao poder Judiciário. E destaca que a ausência de lei não é empecilho a concretização pelo juiz do direito, desde que não inviabilize o preceito constitucional.

Ao que se entende, separação de poderes não pode ser empecilho para reivindicação social, sendo função na busca pela preservação dos direitos e a atuação judicial a forma mais elevada do Estado Democrático do direito, não elaborando políticas públicas, mas resolvendo conflitos e auxiliando nos avanços sociais (ASSIS,2012)

Sendo o STF guardião dos preceitos constitucionais, é seu papel assegurar a efetivação das políticas públicas quando houver o descumprimento pelos demais poderes, assim o que for entendido como mínimo existencial e assegurado por meio de políticas públicas, deve sim o Estado prover, não cabendo a invocação da reserva do possível, nem sendo considerado ingerência de um poder sobre outro.( VOLPE, 2012) uma vez estabelecida a política pública deve ser cumprida, tornando-se direito público subjetivo, sendo o poder judiciário de grande importância para o exercício da cidadania e no cumprimento da justiça social, principalmente no que diz respeito a violação dos direitos fundamentais, cabendo ao judiciário exigir a disponibilização de serviços públicos e a melhoria da qualidade, podendo impor penalidades por força da norma constitucional.

Apesar das necessidades de efetivação, o que é colocado na constituição como direito social e o que de fato recebem os cidadãos encontra grandes problemas. Para tanto, o judiciário é convocado a manifestar-se coagindo o Executivo a fazê-lo, neste ponto é importante analisar quais são os tipos de demandas e o que entende o STF pelo mínimo existencial e reserva do possível nesses casos. Uma vez determinada pelo STF a criação de políticas públicas, estas deveriam constar no plano orçamentário do ano, como diz a Constituição Federal, para que possa ser implementada dentro da reserva do possível. (VOLPE, 2012)

O argumento da reserva do possível somente deve ser usado se o Poder Público demonstrar que a decisão causará mais danos do que benefícios à concretização dos direitos. Para Assis, grande parte da escassez de recursos 
ocorre por escolhas desproporcionais dos poderes, só podendo ser considerada a alegação da reserva do possível se os recursos estiverem equilibrados. Apesar de ser uma limitação, ocorre uma banalização na sua invocação pelo poder público que o usa em juízo ao invés de apresentar outros elementos concretos como impedimento para cumprir as decisões judiciais. (ASSIS,2012)

Os recursos para a realização dos direitos são estipulados pelas leis orçamentárias, destinando a quantidade de recursos a realização de cada direitos social. Tais escolhas podem ser alteradas no decorrer da execução orçamentária se estabelecidas novas escolhas na medida da reserva do possível. As chamadas escolhas trágicas designam com que e com que prioridade serão distribuídos os gastos públicos, respeitando a harmonia econômica geral. ( SCAFF,2011)

Tendo em vista a vastidão de necessidades sociais, coletivas e individuais e a escassez de recursos, as escolhas trágicas são estabelecidas por meio de critérios, para tanto devem ser obedecidos os fundamentos e objetivos descritos na Constituição Federal, tais escolhas são feitas pelo Poder Legislativo estabelecendo metas e sendo aplicadas pelo Poder Executivo implementando os objetivos traçados a curto e médio prazo. (SCAFF, 2011)

O Estado precisa estar em um constante processo dialético, refletindo a realidade social, não devendo ser o modelo jurídico um ideal abstrato. É indispensável a aceitação de opiniões conflitantes que atingem os direitos fundamentais, o Estado precisa de uma organização que permita a livre expressão de ideias para se chegar a uma vontade social e assim a realização do bem comum. (DALLARI, 2003)

O autor ressalta ainda dizendo:

"É preciso levar em conta, no entanto, que o indivíduo não existe isolado e que a coletividade é a soma dos indivíduos. [...] não se há de anular o indivíduo dando precedência sistemática à coletividade, mas também será inadequada a preponderância automática do individual, pois ela poderá levar à satisfação de um indivíduo ou de apenas alguns, em detrimento das necessidades de muitos ou de quase todos, externadas sob a forma de interesse coletivo." (DALLARI,2003,p.130)

Revista do Direito da UNISC, Santa Cruz do Sul, v.1, n. 45, p. 02-30, jan. - abri. 2015. 
Os tribunais tem decidido pelo fornecimento de medicamentos pelo Estado à um grupo de indivíduos para tratamento de doença grave, atendendo o princípio maior do direito à vida digna, uma vez que o SUS tem por objetivo a assistência à saúde seja ela individual ou coletiva, atendendo a quem necessitar. O STJ decidiu ainda que a constituição no artigo 196, aprova o direito a saúde como um dever do Estado, que deve atender as necessidades por meio de políticas sociais e econômicas e proporcionar um tratamento de qualidade e eficaz, atendendo a dignidade da pessoa humana e minimizar seu sofrimento, esclarecendo que a Constituição e seus princípios não devem ser apenas um ideal, mas precisam ter a efetividade de suas normas. (SCAFF,2011)

São inúmeras as demandas judiciais referentes ao direito a saúde em que o poder Judiciário impõe ao Estado o pagamento de medicamentos a pessoas doentes, acrescentada multa diária pelo não cumprimento. principalmente ao fornecimento de medicamentos e tratamentos não abrangidos pelas listas e protocolos do SUS.

Segundo SCAFF (2011), O Estado deve dispor de um valor para arcar com os custos necessários à todos os cidadãos e ainda de valores variáveis a atender a necessidade individual de cada um, seguindo critérios distributivos, indicando escolhas trágicas na opção por políticas públicas que alcancem um número maior de pessoas e de forma mais efetiva. O judiciário, não tem portanto como analisar todos os casos concretos de cada parte, pois prejudicaria a totalidade.

Ao tentar definir como o judiciário pode exercer a judicialização na resolução de casos específicos do direito a saúde, área esta em que mais se encontram casos de intervenção judicial na tentativa de efetivar o direito social. Avaliando se há o direito subjetivo a saúde possível de realização por via judicial. O STF define assim alguns parâmetros para a intervenção judicial. O judiciário não pode obrigar o pagamento de qualquer prestação de saúde que já existe pelo SUS e que foi escolhido pelo paciente na rede particular, porém se a política pública não for eficaz pode o Estado arcar com as despesas. Nas decisões judiciais que são a um indivíduo as prestações necessárias não podem comprometer o funcionamento do SUS, devendo isso ser provado, levando em consideração que

Revista do Direito da UNISC, Santa Cruz do Sul, v.1, n. 45, p. 02-30, jan. - abri. 2015. 
a verba que iria para o SUS irá para o atendimento daquele determinado indivíduo. (NUNES, 2011)

A saúde como estabelece a CF é um direito de todos, tanto individual quanto coletivo, direito público subjetivo, e obrigação do Estado com os indivíduos. A judicialização, como forma de intervenção por parte do judiciário não é o maior problema no Brasil, pois na maioria dos casos o que ocorre é a determinação judicial de uma política já existente mas que não é cumprida. Nesse caso entende o STF que é adequado a obtenção dos medicamentos por via judicial, já que existe uma norma que o garante. Porém se a prestação não for fornecida pelo SUS, é preciso distinguir se isto é feito por omissão legislativa, como na obtenção de medicamento não registrado na ANVISA, não podendo o administrativo concede-lo, pois este é requisito básico para o fornecimento, atestando a segurança e o benefício do produto. (SCAFF, 2011)

Nesse sentido o Estado defende a ideia de que o dever seria apenas de fornecer medicamentos contemplados na relação de medicamentos do Rename, os considerados medicamentos essenciais, e aos hipossuficiente, porem, estabelece a constituição que este direito é de todos devendo estar atrelado a necessidade e a eficácia do medicamento para o paciente. (BERNARDI, 2007)

$\mathrm{Na}$ hipótese de decisão administrativa de não fornecer aquela ação de saúde, precisa haver uma motivação para tal, se o SUS fornecer tratamento alternativo e se este for eficaz, deve ser privilegiado este e não outro que o paciente escolher, respeitando primeiramente as políticas públicas já estabelecidas. Se o indivíduo provar que a medida disponibilizada pelo SUS não é eficaz em seu caso, há a possibilidade do Poder judiciário ou administrativo decidir custear outra medida. Outra hipótese que deve ser avaliada é se há tratamento para tal patologia na rede pública, se a existência de tratamento é meramente experimental, e por isso não pode ser fornecido pelo SUS pois ainda é pesquisa médica. Ou no caso de tratamentos novos, onde há tratamento mas não é utilizado pelo SUS, sendo já acessível na rede privada. Deve ser feita revisão periódica dos protocolos de saúde, cabe nesse caso impugnação judicial tanto coletiva quanto individual. (SCAFF, 2011)

Revista do Direito da UNISC, Santa Cruz do Sul, v.1, n. 45, p. 02-30, jan. - abri. 2015. 
Segundo o entendimento de Silvia Waltrick Bernardi (2007), não há como sujeitar o paciente a uma lista pré-estabelecida de medicamentos, sujeitando-o a não receber o tratamento adequado por este não constar na lista.

Para Fernando Facury Scaff, (2011), Pleitear direito individual no judiciário seria transferir a fila do SUS ao tribunal, sendo que alguns não a obteriam por não ser um sistema simultâneo, dando apenas a quem pedir. O que se deve buscar no judiciário é o preenchimento das lacunas, atualizando o direito à saúde conforme a disponibilização dos recursos públicos que se dá de forma progressiva a atender as necessidades da população, reserva do possível está que delimita escolhas para onde destina-se o orçamento público não podendo ele atender a todos da melhor maneira.

Há de se considerar que não há nenhum país que tenha recursos financeiros suficientes para atender a todas as exigências e proporcionar a total satisfação dos direitos sociais, não podendo prover tudo a todos. mesmo que de forma lenta e progressiva, os recursos devem ser usados a fim de ampliar os direitos previstos constitucionalmente. Não podendo ter a plena realização de todos os direitos sociais a todos os cidadãos, é necessário escolher a parte dos recursos que vai para cada direito, está é uma escolha política, que não pode ser feita por tribunais. Não pode ser atribuído todos os recursos à saúde deixando outros direitos como educação e segurança sem efetivação. (NUNES, 2011) Assim, o direito a saúde decorre do desenvolvimento tecnológico da medicina e da disponibilidade de recursos públicos.

Do mesmo modo, prestação de saúde gratuita não pode reduzir-se a serviços médicos e medicamentos de pessoas que encontrem-se doentes mas devem ser políticas mais complexas, que envolvam habitação, higiene, alimentação, saneamento básico, alimentação e cuidados com a saúde através de vacinação e bons hospitais com recursos avançados. Porém, aqui também o Estado precisa fazer uma escolha política, pois não há orçamento para satisfazer todas as necessidades de saúde de toda a população. Há de se observar se devese priorizar a saúde comunitária com programas para todos ou o diagnostico e

Revista do Direito da UNISC, Santa Cruz do Sul, v.1, n. 45, p. 02-30, jan. - abri. 2015. 
medicamentos de uma saúde individualista, privilegiando as necessidades de cada doente. (NUNES, 2011)

Por outro lado, a realocação de recursos que seriam destinados a políticas públicas que beneficiariam um maior numero de pessoas com menos rendimentos, para custear tratamentos e medicamentos a um só paciente acaba afetando a coletividade e a qualidade de acesso aos que seriam beneficiados na política pública. (NUNES, 2011)

Além disso, o judiciário só conhece os casos que são levados até ele, enquanto outros tantos com o mesmo problema ficam desamparados, levando em consideração que a maioria dos necessitados não tem acesso ao tribunal, não sendo assim efetivo a todos. Devia então o Estado estar ciente de todos os que necessitam, porem este procedimento inviabilizaria rapidamente a promoção de saúde a todos, afetando principalmente os mais pobres. Entretanto, se a ação for coletiva, reivindicando o mesmo direito a todos e não apenas ao autor da demanda, poderá garantir o benefício a todos. (NUNES, 2011)

O STF alega caber ao judiciário a garantia do cumprimento das leis e a efetivação do direito à saúde e à vida, direitos esses que devem prevalecer sobre qualquer norma jurídica, salientando que, entre proteger o direito inalienável à vida, ou deixar prevalecer sobre este um interesse financeiro do Estado, a posição a ser tomada é de respeito à vida. (NUNES, 2011)

Os pacientes com graves doenças, considerados vulneráveis e hipossuficientes necessitam de permanente assistência e tratamentos, a delicada condição os mantem dependente do amparo tecnológico que permite-Ihes viver, tratamentos capazes de prolongar e melhorar na qualidade de vida do paciente, o tratamento e os medicamentos tornam-se a única forma de sobreviver com alguma qualidade de vida. A vida destes pacientes não é fácil e torna-se inviável sem o adequado suporte técnico a ser viabilizado, segundo a Constituição, em grande parte pelo Estado. Para Bernardi, o auxilio deve ser debatido pelo judiciário e pela sociedade, mas "limitar ou restringir o acesso a esse suporte é negar o direito constitucional à vida, à saúde e a dignidade, que deve indiscutivelmente ser priorizada frente a outras necessidades [...]" (BERNARDI, 2007, p.180)

Revista do Direito da UNISC, Santa Cruz do Sul, v.1, n. 45, p. 02-30, jan. - abri. 2015. 
Apesar das ações individuais não contemplarem plenamente o direito previsto constitucionalmente, que devia ser focado na sociedade como um todo, pode sim ser pleiteado aos tribunais. Nesse ponto de vista as ações judiciais devem contemplar o direito não apenas para si, mas busca-lo para todos. (SCAFF, 2011).

\section{O SUPREMO TRIBUNAL FEDERAL E O RECONHECIMENTO DO DIREITO À SAÚDE COMO NECESSÁRIO A PRESERVAÇÃO DA VIDA}

Considerando que a Constituição de 1988 foi a primeira a conferir a devida importância à saúde, tratando-a de fato como direito fundamental, o que consequentemente obrigou os Estados a atribuir sentido concreto aos direitos sociais, passamos a análise de um caso concreto da efetivação do direito à saúde. Cuida-se de um pedido de suspensão de tutela antecipada, ajuizada pela União contra a decisão do juízo da 2ª Vara Federal de Blumenau- SC (Ação Civil Pública № 2008.72.05.000566-7) e mantida pelo Tribunal Regional Federal da 4" Região (Agravo de Instrumento n. $2009.04 .00 .029752-8 / S C$ ).

Neste fato, as partes envolvidas no polo ativo foi o Ministério Público e o paciente paradigma Edgar Depine. O Ministério Público ajuizou ação civil pública requerendo a antecipação de tutela contra a União Federal e obrigando-a a importar o medicamento Isentress (REALTEGRAVIR), para atender Edgar Depine e os demais pacientes infectados por HIV e que possuem resistência aos demais medicamentos com prescrição médica na subseção Judiciária de Blumenau (JUSBRASIL,2010).

O juízo determinou a inclusão do Estado de Santa Catarina e do Município de Blumenau no polo passivo da ação, considerando a responsabilidade solidária entre os entes da federação. Assim, incluiu diante de revisão a terapia prescrita ao paciente, o medicamento intelence tendo este o mesmo princípio ativo etravirine, e concedeu antecipação de tutela, sob pena de multa diária de $R \$ 1.000,00$ (mil reais) determinando que a união adquira por meio de importação ou qualquer outro meio legal os medicamentos e que a União, Estado de Santa Catarina e

Revista do Direito da UNISC, Santa Cruz do Sul, v.1, n. 45, p. 02-30, jan. - abri. 2015. 
Município de Blumenau forneçam gratuitamente a todos os usuários do SUS daquele município portadores de HIV e com prescrição médica indicada para tal tratamento, em especial ao mencionado paciente Edgar Depine, na quantia inicial de 12 frascos de cada medicamento (JUSBRASIL,2010).

Em decorrência do indeferimento do efeito suspensivo requerido pela União, a mesma ingressou com o pedido de suspensão de execução de liminar ao Tribunal Regional Federal da 4⿳亠丷a Região, que restou prejudicado pela interposição de agravo de instrumento analisado pela Desembargadora Federal Silvia Maria Gonçalves Goraieb. Com isso, novamente a União ajuizou, pedido de suspensão da tutela antecipada a esta Corte, argumentando a grave lesão à ordem, à saúde e à economia pública (JUSBRASIL,2010).

Dentre seus argumentos, a União relatou que o fornecimento dos referidos medicamentos de alto custo ISENSTRESS (raltegravir) e INTELENCE (etravirine) acabaria por inviabilizar o funcionamento adequado do sistema público de saúde e prejudicaria os serviços de saúde básica em relação ao restante da população. Isto é, em seu posicionamento disponibilizar de forma ampla e gratuita os medicamentos destinados ao tratamento de HIV, com um custo final alto ao Poder Público, e sem elaboração de estudos técnicos anteriores indispensáveis para examinar a real necessidade, acabaria diminuindo a capacidade financeira do fornecimento de outros benefícios considerados relevantes a sociedade (JUSBRASIL,2010).

Ainda, destacou a parte requente a ausência de comprovação da segurança e da eficácia do medicamento INTELENCE (etravirine), sendo que não possuía registro na ANVISA, e da existência de outros terapêuticos oferecidos na rede pública para o tratamento da AIDS, alegou que não haveria a devida previsão orçamentária para a aquisição da medicação. Sustentando ainda que as prestações de saúde devem ser executadas dentro da reserva do possível (JUSBRASIL,2010).

Considerando os argumentos acima apresentados, o Desembargador Federal Carlos Eduardo Thompson Flores Lenz, relator do agravo de instrumento n. 2008.04.00.017501-7/SC, deu parcial provimento ao recurso, suspendendo o 
fornecimento da medicação, ressalvando que o que já havia sido entregue não poderia ser recolhido. Os fundamentos usados pelo Desembargador foram da ausência de prova pericial, que acarretaria em prejuízos ao SUS e a todos os brasileiros. No entanto, após a produção de prova pericial, o Juiz Federal substituto Clenio Jair Schulze concedeu medida liminar, considerando que o medicamento é necessário e indispensável à manutenção da vida do paciente paradigma Edgar Depine, com base em laudo pericial (JUSBRASIL,2010).

Foram interpostos 9 agravos no decorrer do procedimento. No que tange a decisão, é importante considerar alguns fatores. O primeiro fator é se existe ou não políticas públicas ou estatais que englobem a prestação de saúde pleiteada pela parte, necessariamente no que compete ao SUS. Caso a prestação de saúde não esteja entre as políticas do SUS, é imprescindível distinguir se decorre uma omissão legislativa ou administrativa. Também, deve-se considerar a existência de motivação para o não fornecimento de determinada ação com o objetivo de garantir a prestação de saúde (JUSBRASIL,2010).

Nesse aspecto, existem situações em que o SUS decidiu não custear por entender que inexistem evidências para autorizar sua inclusão. Em outras hipóteses, o SUS pode fornecer tratamento alternativo, mas que não se encaixa com o que paciente precisa, ou, não possui nenhum tratamento específico para determinada patologia. É sabido que obrigar a rede pública a financiar toda e qualquer ação de prestação de saúde geraria grave lesão à ordem administrativa e poderia comprometer o funcionamento do SUS e dos atendimentos médicos a população necessitada (JUSBRASIL,2010).

Assim, considerando esses quesitos, a decisão ressalvou que o tratamento fornecido pelo SUS em detrimento a opção diversa escolhida pelo paciente, sempre que não comprovada a ineficácia ou impropriedade da política de saúde existente, deverá haver a concessão do direito à saúde pleiteado. Assim, a omissão administrativa no tratamento de determinada patologia pode ser objeto de impugnação judicial, tanto por ações individuais quanto coletivas (JUSBRASIL,2010).

Revista do Direito da UNISC, Santa Cruz do Sul, v.1, n. 45, p. 02-30, jan. - abri. 2015. 
Não obstante, é mister que haja instrução processual, com ampla produção de provas para a concessão de medida cautelar. Em relação ao caso em epígrafe, os documentos acostados no autos demonstram que o paciente paradigma Edgar Depine é portador do vírus HIV há mais de 10 anos, e que este se submete a tratamentos antirretroviral. Foi constatado um quadro de regressão relativo a imunidade, sendo então receitado pelo infectologista Dr. Amaury Mielle (CRM 5889) os medicamentos requeridos, pois os já utilizados apresentaram falha terapêutica. Além disso, foi devidamente realizada a prova pericial que também constatou ser necessário e indispensável a vida do paciente a concessão dos medicamentos (JUSBRASIL,2010).

De modo que se for interrompido o uso da medicação, o medicamento não fara mais efeito, o que repercutira na queda acentuada da imunidade do paciente podendo levar a óbito, conforme laudo pericial. Em contrapartida quando analisadas as razões da União, quanto ao registro na ANVISA restou comprovado que o Intelence, cujo princípio ativo é a Etravirina, produzido pela empresa JANSSEN-CILAG FARMACÊUTICA Itda., foi registrado sob o n.․ 112363391, válido até $02 / 2014$, o que atesta sua segurança para 0 consumo (JUSBRASIL,2010).

Assim, os documentos juntados nos autos e os fundamentos da decisão impugnada, restaram suficientes para comprovar que o paciente em questão necessita com urgência do fornecimento destes medicamentos, levando em conta o que preconiza a Lei Federal n. 9.313/96 que garante o acesso a medicamentos antirretrovirais pelos SUS para todas as pessoas acometidas pela doença: art. $1^{\circ}$ "os portadores do HIV (vírus da imunodeficiência humana) e doentes de AIDS (Síndrome da Imunodeficiência Adquirida) receberão gratuitamente do Sistema Único de Saúde, toda a medicação necessária a seu tratamento" (BRASIL, Lei 9.313/96).

A União argumentou que a concessão causaria lesão à economia pública, no entanto, não foi comprovado dano aos cofres federais, limitando-se a requerer a aplicação da reserva do possível. Com isso, não observando quaisquer casos de grave ofensa a ordem e a economia pública o Plenário do Supremo Tribunal

Revista do Direito da UNISC, Santa Cruz do Sul, v. 1, n. 45 , p. 02-30, jan. - abri. 2015. 
Federal, por unanimidade, negou provimento a nove agravos regimentais interpostos, para manter determinações judiciais que ordenavam ao Poder Público fornecer remédios de alto custo ou tratamentos não oferecidos pelo Sistema único de Saúde (SUS) a pacientes portadores de doenças graves (JUSBRASIL,2010).

\section{CONCLUSÕES}

Fica para nós o desafio de que os direitos sociais possam permear a política macro econômica, de forma a envolver a política fiscal, a política monetária e a política cambial.

As instituições econômicas internacionais devem levar em grande consideração a dimensão humana de suas atividades e o forte impacto que as políticas econômicas pode ter nas economias locais especialmente em um mundo cada vez mais globalizado.

Devemos romper com os paradoxos que decorrem das tensões entre a tônica includente voltada para a promoção dos direitos sociais, consagrada nos relevantes tratados de proteção dos direitos humanos da ONU (por exemplo, o Pacto Internacional dos Direitos Econômicos, Sociais e Culturais) e, por outro lado, a dimensão excludente ditada pela atuação especialmente das agências econômicas especializadas (como por exemplo o Banco Mundial e o Fundo Monetário Internacional), na medida em que suas políticas, orientadas pela "condicionalidade", submete países em desenvolvimento a modelos de ajuste estrutural incompatíveis com os direitos humanos.

Flavia Piovezan, citando o autor Jack Donnelly, aponta para a conseqüência do referido anteriormente quando nos trás que:

"Mercados livres são economicamente análogos ao sistema político baseado na regra da maioria, sem, contudo, a observância aos direitos das minorias. As políticas sociais, sob esta perspectiva, são essenciais para assegurar que as minorias, em desvantagem ou privadas pelo mercado, sejam consideradas com o mínimo respeito na esfera econômica" (PIOVEZAN, 2003. p. 259).

Revista do Direito da UNISC, Santa Cruz do Sul, v.1, n. 45, p. 02-30, jan. - abri. 2015. 
Mas não se deve atentar somente para os organismos econômicos internacionais, e sim, também, para a necessidade de acentuar a responsabilidade social do setor privado, especialmente das empresas multinacionais, na medida em que constituem as grandes beneficiárias do processo de globalização.

Em razão da indivisibilidade dos direitos humanos, a violação aos direitos econômicos, sociais e culturais exercido pela exacerbada postura neoliberal na globalização econômica, propicia, sem dúvida, a violação aos direitos civis e políticos, eis que a vulnerabilidade econômico-social leva à vulnerabilidade dos direitos civis e políticos.

Se os direitos civis e políticos mantêm a democracia dentro de limites razoáveis, os direitos econômicos e sociais estabelecem os limites adequados aos mercados. Todavia, sabemos muito bem que somente mercados e eleições, por si só, não são suficientes para assegurar direitos humanos para todos.

Por fim, importante referir que, para a implementação mais eficaz dos direitos humanos, principalmente os direitos econômicos, sociais e culturais, emerge o desafio da construção de um novo paradigma, pautado por uma agenda de inclusão, que seja capaz de assegurar um desenvolvimento sustentável, mais igualitário e democrático, nos planos local, regional e global.

A saúde no Brasil é um assunto polêmico amplamente pleiteado nos tribunais, isto por que, sem dúvida, é o pressuposto base para o pleno exercício dos direitos. A presente pesquisa teve por objetivo analisar o direito à saúde no Estado Brasileiro e a gratuidade na disponibilização de medicamentos. Analisando de forma sintética a evolução histórica do direito a saúde na Constituição Brasileira, assim reconhecido como direito fundamental social a qual estrutura as bases do Sistema Único de Saúde, de forma igualitária e universal. Observando que esta não restringe-se apenas aos medicamentos, atendimento médico e internação hospitalar, mas é um conjunto de diversas ações como a prevenção de doenças, a alimentação de qualidade, higiene entre outros fatores de fundamental importância para a saúde do indivíduo.

O direito a saúde é de máxima importância para o desenvolvimento do ser humano e para uma vida digna, devendo ser respeitado seu grau mínimo a todos 
os cidadãos, cabendo ao Estado efetiva-lo por meio de políticas públicas que garantam condições saudáveis e dignas ao indivíduo, tratando e prevenindo possíveis enfermidades.

Observados os limites encontrados na efetivação do direito a saúde, tendo em vista as necessidades da população e a escassez de recursos, assim como a observância de princípios como o mínimo existencial, que deve ter sua garantia efetivada para que sejam garantidas as condições mínimas de existência e a grande necessidade da população frente aos escassos recursos de que dispõe o Estado para realiza-los. Assim, mesmo não tendo infinitos recursos, tem o Estado o dever de prover ao menos as condições mínimas e dignas a todos, não podendo deixar de forma alguma os indivíduos a mercê da própria sorte.

No que se refere ao dever do estado de fornecer saúde de qualidade a todos, relacionando este ao de fornecer tratamentos médicos e medicamentos de altos custos. Assim como os não relacionados na lista do Sistema Único de Saúde. Rompendo as barreiras para a efetivação dos direitos sociais, e sabido da dificuldade de prover tudo a todos o Estado deve respeitar o mínimo, e caminhar sempre em direção ao máximo na medida do possível.

A constituição impõe ainda que este é direito de todos, por tanto, considerase também direito à igualdade, igualdade de tratamento a todos os cidadãos. Dando especial atenção àqueles que não possuem condições financeiras para arcar com os altos custos de tratamentos. Assim não podemos esquecer, que quando falamos em direito a saúde, falamos da dignidade da pessoa humana e do direito maior de todo ser humano, a vida. A vulnerabilidade dos pacientes que sofrem por graves doenças pede um judiciário ativo, que lute pela realização da sua dignidade.

A questão toma maior grau de complexibilidade ao avaliar pontos como as demandas judiciais em que o direito encontra-se subjetivado ao indivíduo, problemática que envolve as demandas de direitos fundamentais sociais. As ações coletivas mostram-se uma das mais adequadas formas para questionar o poder judiciário quanto à efetivação de políticas públicas referentes ao direito à 
saúde, vez que insere a discussão em âmbito nacional, garantindo o direito da demanda não apenas ao indivíduo, mas a toda a sociedade.

\section{REFERÊNCIAS}

ALEXY, Robert. Direito a ações estatais positivas (Direitos a prestações em sentido amplo). In: Alexy; Robert. Teoria dos Direitos Fundamentais. 2 ed. São Paulo: Malheiros Editores, 2012, p. 433 - 519.

ASSIS, Victor Hugo Siqueira De. O Controle Judicial das Políticas Públicas: a problemática da efetivação dos direitos fundamentais sociais. Revista Espaço jurídico. p.283-296. Joaçaba: Editora Unoesc, 2012.

BARCELLOS, Ana Paula de. A eficácia jurídica dos princípios constitucionais: o princípio da dignidade da pessoa humana. 3.ed. revista e atualizada. Rio de Janeiro: Renovar, 2011.

BARROSO, Luís Roberto. O controle de constitucionalidade no direito brasileiro: exposição sistemática da doutrina e análise crítica da jurisprudência. 6.ed. rev. e atual. São Paulo: Saraiva, 2012.

BENVENUTO, Jayme. Indivisibilidade e justiciabilidade dos Direitos Humanos: aspectos da discussão nos planos nacional e internacional. In: BAEZ, Narciso Leandro Xavier; LEAL, Rogério Gesta; MEZZAROBA, Orides. (Cords).

Dimensões materiais e eficaciais dos direitos fundamentais. São Paulo: Conceito Editorial, 2010.

BERNARDI, Silvia Waltrick. Dignidade humana e o direito fundamental à saúde. p.177-196. In: BAEZ, Narciso Leandro Xavier; BARRETO, Vicente. Direitos humanos em evolução. Joaçaba: Editora Unoesc, 2007.

BRASIL.Constituição da República Federativa do Brasil. Brasília: Senado Federal, Subsecretaria de Edições Técnicas,2012.

BRASIL, Lei 9.313/96. Disponível em:<http://www.planalto.gov.br/ccivil 03/leis/19313.htm> Acesso em: 10 de outubro de 2014.

BRASIL. Lei no 8.142, de 28 de dezembro de 1990. Disponível em:<http://www.planalto.gov.br/ccivil 03/leis/l8142.htm>.Acesso em: 27 de maio de 2014.

Revista do Direito da UNISC, Santa Cruz do Sul, v.1, n. 45, p. 02-30, jan. - abri. 2015. 
BRASIL. Lei no 8.080, de 19 de setembro de 1990. Disponível em:<http://www.planalto.gov.br/ccivil 03/leis/l8080.htm>. Acesso em: 27 de maio de 2014.

OLIVEIRA, Erival da Silva. Direitos humanos. 2.ed. São Paulo: Editora Revista dos Tribunais,2011.

CAVALHEIRO, Andressa Fracaro. $\mathbf{O}$ direito à saúde no Brasil: A estratégia saúde da família como possível mecanismo densificador. 1.ed. Maringá: Humanitas Vivens, 2013.

CLÈVE, Clèmerson Merlin. A eficácia dos Direitos Fundamentais Sociais. Revista Crítica Jurídica. Curitiba: UNIBRASIL, № 22, p.17-29, jul./dez.2003.

DALLARI, Dalmo de Abreu. Elementos de teoria geral do Estado. Editora saraiva. 24.e.d. 2003.

PIOVEZAN, Flávia. Proteção Internacional dos Direitos Econômicos, Sociais e Culturais.In. Direitos Fundamentais Sociais: Estudos de Direito Constitucional, Internacional e Comparado. Org. Ingo Wolfgang Sarlet, Rio de Janeiro: Renovar, 2003.

JUSBRASIL. STF, suspensão de tutela antecipada: STA 260 SC. Disponível em: <http://stf.jusbrasil.com.br/jurisprudencia/9152113/suspensao-de-tutelaantecipada-sta-260-sc-stf> Acesso em: 10 de outubro de 2014.

MORAES, Alexandre de. Direito Constitucional. 13.ed. Atualizada com a EC n. ${ }^{\circ}$ 39/02. São Paulo: Editora Atlas S.A., 2003

NUNES, António José Avelãs; SCAFF, Fernando Facury. Os Tribunais e o Direito à Saúde. Porto Alegre: Livraria do Advogado Editora, 2011.

OLIVEIRA, Erival da Silva. Direitos humanos. 2.ed. São Paulo: Editora Revista dos Tribunais,2011.

Organização Mundial da Saúde. Constituição da Organização Mundial da Saúde (OMS/WHO) 1946. Disponível em:

$<$ http://www.direitoshumanos.usp.br/index.php/OMS-

Organiza\%C3\%A7\%C3\%A3o-Mundial-da-Sa\%C3\%BAde/constituicao-daorganizacao-mundial-da-saude-omswho.html>.Acesso em: 16 de set. 2014

PETERSEN, Letícia Lassen. Direito Constitucional à Saúde e a sua efetivação. In: COSTA, Marli M.M. da; HERMANY, Ricardo; SODER, Rodrigo Magnos. (Org). Direito, Cidadania \& políticas públicas. p.245-260 Porto Alegre: Imprensa livre,2011.

Revista do Direito da UNISC, Santa Cruz do Sul, v.1, n. 45, p. 02-30, jan. - abri. 2015. 
PROCOPIUCK, Mario. Políticas Públicas e Fundamentos da Administração Pública: Análise e avaliação governança e redes de políticas administrativas Judiciárias. São Paulo: Editora Atlas S.A., 2013.

SANTOS, Fernando Ferreira dos. Princípios Constitucionais da Dignidade da Pessoa Humana. São Paulo: Celso Bastos Editor: Instituto Brasileiro de Direito Constitucional, 1999.

SILVA. Flávia Martins André da. Direitos Fundamentais. Disponível em: <http://www.direitonet.com.br/artigos/exibir/2627/Direitos-Fundamentais>. Acesso em: 06 de outubro de 2014.

SILVA, José Afonso da. Curso de direito constitucional positivo. 30. Ed., ver. Atual. São Paulo: Malheiros, 2008.

SOARES, Juliana. Disponível em: <http://www.direitonet.com.br/artigos/exibir/1293/A-justiciabilidade-dos-DireitosSociais>. Acesso em maio de 2014

VOLPE, Karina Rocha Martins. A judicialização dos Direitos sociais estudos de caso na ótica do mínimo existencial. Revista espaço jurídico. Editora unoesc, Joaçaba n.1 jan./jun. 2012. 